\title{
QUEEN'S
UNIVERSITY
BELFAST
}

\section{Examining intraspecific multiple predator effects across shifting predator sex ratios}

\author{
Cuthbert, R. N., Dalu, T., Wasserman, R. J., Weyl, O. L. F., Froneman, P. W., Callaghan, A., \& Dick, J. T. A. \\ (2020). Examining intraspecific multiple predator effects across shifting predator sex ratios. Basic and Applied \\ Ecology, 45, 12-21. https://doi.org/10.1016/j.baae.2020.03.002
}

Published in:

Basic and Applied Ecology

Document Version:

Peer reviewed version

Queen's University Belfast - Research Portal:

Link to publication record in Queen's University Belfast Research Portal

\section{Publisher rights}

Copyright 2021 Elsevier.

This manuscript is distributed under a Creative Commons Attribution-NonCommercial-NoDerivs License

(https://creativecommons.org/licenses/by-nc-nd/4.0/), which permits distribution and reproduction for non-commercial purposes, provided the author and source are cited.

\section{General rights}

Copyright for the publications made accessible via the Queen's University Belfast Research Portal is retained by the author(s) and / or other copyright owners and it is a condition of accessing these publications that users recognise and abide by the legal requirements associated with these rights.

Take down policy

The Research Portal is Queen's institutional repository that provides access to Queen's research output. Every effort has been made to ensure that content in the Research Portal does not infringe any person's rights, or applicable UK laws. If you discover content in the Research Portal that you believe breaches copyright or violates any law, please contact openaccess@qub.ac.uk. 
2 Examining intraspecific multiple predator effects across shifting predator sex

\section{3 ratios}

4 Ross N. Cuthbert ${ }^{\text {a, b, c, } * \text {, Tatenda Dalu }}{ }^{\text {d, e }}$, Ryan J. Wasserman ${ }^{\text {f, e }}$, Olaf L. F. Weyl ${ }^{\text {b }}$, P. William

5 Froneman $^{\mathrm{g}}$, Amanda Callaghan $^{\mathrm{c}}$, Jaimie T. A. Dick ${ }^{\mathrm{a}}$

6 anstitute for Global Food Security, School of Biological Sciences, Queen's University Belfast,

7 Belfast BT9 5DL, Northern Ireland

$8{ }^{\mathrm{b}}$ DSI/NRF Research Chair in Inland Fisheries and Freshwater Ecology, South African Institute

9 for Aquatic Biodiversity, Makhanda 6140, South Africa

10 'Ecology and Evolutionary Biology, School of Biological Sciences, University of Reading,

11 Harborne Building, Reading RG6 6AS, England

$12{ }^{d}$ Department of Ecology and Resource Management, University of Venda, Thohoyandou 0950,

13 South Africa

14 eSouth African Institute for Aquatic Biodiversity, Makhanda 6140, South Africa

$15{ }^{f}$ Department of Biological Sciences and Biotechnology, Botswana International University of 16 Science and Technology, Palapye, Botswana

$17{ }^{g}$ Department of Zoology and Entomology, Rhodes University, Makhanda 6140, South Africa

18

19

20

*Corresponding author. Tel.: +44 2842728230.

E-mail address: rossnoelcuthbert@gmail.com. 


\section{Abstract}

25 Predator-predator interactions, or "multiple predator effects" (MPEs), are pervasive in the

26 structuring of communities and complicate predictive quantifications of ecosystem dynamics.

27 The nature of MPEs is also context-dependent, manifesting differently among species, prey

28 densities and habitat structures. However, there has hitherto been a lack of consideration for the

29 implications of intraspecific demographic variation within populations for the strength of MPEs.

30 The present study extends MPE concepts to examine intraspecific interactions among male and

31 female predators across differences in prey densities using a functional response approach.

32 Focusing on a copepod-mosquito model predator-prey system, interaction strengths of different

33 sex ratio pairs of Lovenula raynerae were quantified towards larval Culex pipiens complex prey,

34 with observations compared to both additive and substitutive model predictions. Copepods

35 exhibited destabilising Type II functional responses in all treatments, with female copepods

36 significantly more voracious than males under multiple predator groups. Lovenula raynerae

37 exhibited significantly negative MPEs overall which resulted in prey risk reductions. However,

38 whilst not statistically clear, the magnitude of antagonistic interactions subtly differed among

39 predator-predator compositions and prey densities, with female-female antagonisms generally

40 prevalent at low prey densities, and male-male negative interactions greater under high prey

41 densities. Mixed-sex copepod group predation was predicted by both additive and substitutive

42 models, and additive models generated significantly higher consumption estimates than

43 substitutive equivalents given that their predictions were based on the absence of antagonistic

44 non-trophic interactions. We propose the importance of internal population sex demographics as 
45 a further context-dependency which influences the nature of MPEs, with demographic

46 implications requiring investigation across other taxonomic and trophic groups.

\section{Keywords:}

48 Temporary pond; functional response; predator-predator interaction; sex demographic; Lovenula

49 raynerae; Culex pipiens

50

51

52

53

54

55

56

57

58

59

60

61

62

63 
Predation has a pervasive impact on community dynamics, with implications for structuring and

66 functioning at the ecosystem-level (Hairston et al. 1960; Sih et al. 1985; Estes et al. 2011;

67 Waterkeyn et al. 2016). Quantifications of trophic dynamics are, however, often based on paired consumer-resource interaction strengths, which ignore context-dependencies that influence predatory impacts (Bolker et al. 2003; Werner \& Peacor 2003; Schmitz 2007). In particular, the assumption that predators act independently ignores "multiple predator effects" (MPEs) which may alter prey risks (Soluk 1993). Indeed, multiple predator species which share resources are commonplace in ecosystems, resulting in interactions such as interference and intraguild predation which may alter predatory efficiencies (Sih et al. 1998). In this context, predators are assumed to act non-independently when observed prey consumption levels differ from those predicted from models. Multiple predator effects may manifest in three broad ways: (1) antagonistically, resulting in prey risk reductions (Rosenheim et al. 1995; Wasserman et al. 2016b); (2) additively, where prey risk is well-predicted from individual predators (Chang 1996;

78 Barrios-O’Neill et al. 2014), or; (3) synergistically, resulting in prey risk enhancements (Soluk

79 1993; Losey \& Denno 1998). Accordingly, quantitative understandings of the nature of MPEs

80 are integral to robust community- and ecosystem-level models (Sih et al. 1998; McCoy et al.

81 2012; Sentis \& Boukal 2018), and may, for example, elucidate the implications of predator

82 extirpation within communities.

83 Whilst the strength of MPEs has been examined under single, or just a few, prey densities

84 (Harvey et al. 2004; Griffen 2006; Porter-Whitaker et al. 2012), it is well-established that 85 predation is also density-dependent, with efficiencies differing across levels of prey availability 86 (Abrams 1982, 2000; Cuthbert et al. 2019b). Fundamentally, the shape of resource use (e.g. 
87 predation) rates across resource (e.g. prey) densities is known as the functional response (Holling

88 1959), and different functional response forms have important implications for prey population

89 stabilities (Hassell 1978). Whilst the functional response is a classical ecological concept,

90 regularly applied to quantify interaction strengths in the context of biological control (Cuthbert et

91 al. 2018b), invasion science (Dick et al. 2014) and optimal foraging theory (Abrams 1982),

92 relatively few studies have employed a functional response approach to quantify emergent

93 MPEs, with contrasting results reported (Soluk 1993; Losey \& Denno 1998; Barrios-O’Neill et

94 al. 2014; Wasserman et al. 2016b). Centrally, the attack rate and handling time (inverse

95 maximum feeding rate) parameters of functional response curves offer insights into the strength

96 of MPEs across a spectrum of prey densities. Accordingly, the comparative functional response

97 approach lends itself to quantifications of multiple predator effects.

Previously, MPE studies have considered predator-predator interactions at the interspecific level

99 (Soluk 1993; Sih et al., 1998; Vance-Chalcraft \& Soluk 2005). However, more recently, the nature of MPEs has been examined for both heterospecific and conspecific predator

101 combinations (Lampropoulos et al. 2013; Barrios-O’Neill et al. 2014; Wasserman et al. 2016b).

102 Nevertheless, there has been a distinct lack of consideration for differences in conspecific

103 interactions associated with population demographics. This is despite sex and reproductive status 104 having been shown to significantly alter interaction strengths by individual predators across 105 multiple prey densities (Cuthbert et al. 2019b). Accordingly, we thus propose intraspecific 106 interactions based on key demographic characteristics to be an appropriate context within the 107 MPE framework. Therefore, given the lack of consideration for emergent MPEs across 108 demographic variations, we here examine the implications of compositional sex ratio change for 109 the nature of MPEs, using the numerically abundant and predatory paradiaptomid copepod 
Lovenula raynerae Suárez-Morales, Wasserman \& Dalu 2015 (Suárez-Morales et al. 2015)

feeding on larval mosquito prey as a model predator-prey system. Lovenula raynerae is a temporary pond specialist copepod, which hatches from egg banks within substrate following inundation with water. Mass-hatching events exhibited in these aquatic systems make intraspecific interactions pervasive, and perhaps more common than those at the interspecific level. Further, this copepod species occupies top trophic levels in temporary pond ecosystems for much of the hydroperiod (Dalu et al. 2016), exerts substantial predatory impact on lower trophic groups (Wasserman et al. 2016a; Cuthbert et al. 2018a) and is widespread and often dominant in temporary pond systems in its native range (Wasserman et al. 2018). Sex-skewed demographics of this predator are known to develop over the hydroperiod due to selective process such as predation (Wasserman et al. 2018). Therefore, the implications of MPEs may vary over the course of hydroperiod in temporary ponds, owing to shifting population demographics over relatively rapid timescales.

We firstly determine the functional responses of male and female L. raynerae when present singularly with larval mosquito prey. We then quantify multiple predator functional responses in mixtures of conspecific pairs (i.e. female-female, male-male and female-male). We use these observations as a framework to decipher whether MPEs are emergent in this study system, and whether the strength of MPEs is modulated by variations in sex ratio. To do this, we employ both additive and substitutive models to predictively quantify MPEs, before comparing the estimates generated by both modelling techniques across prey densities. The relative appropriateness of additive and substitutive experimental designs has been debated in the context of ecological community dynamics (Griffen 2006; O’Gorman et al. 2008; Lampropoulos et al. 2013). Whilst additive designs compare the observed predation rate of individuals to the consumption of 
133 predators in combination, substitutive designs alter the diversity of predator combinations, in

134 turn fixing total predator abundance. As such, inferences from additive designs are made on the

135 basis of experimental increases in predator density, whilst substitutive designs alter the

136 proportional composition of predator groupings to decipher the relative effect of interactions

137 among different predator types. Our experimental design enables explicit comparison of

138 predictions from additive and substitutive models in the mixed-sex predator treatment.

139 Ultimately, our study aims to examine the potential importance of intraspecific sex

140 demographics for the strength of MPEs in temporary ponds and other ecosystems.

\section{Materials and methods}

\section{Animal collection and experimental design}

144 Adult L. raynerae were collected from ephemeral ponds in Bathurst, Eastern Cape, South Africa

$145 \quad\left(33^{\circ} 29^{\prime} 21.7^{\prime \prime S} 26^{\circ} 49^{\prime} 48.2^{\prime \prime E}\right)$ using a $200 \mu \mathrm{m}$ mesh zooplankton net and transported in source

146 water to a controlled environment room at Rhodes University, Makhanda (Grahamstown). Adult

147 males and females (male, $4.71 \mathrm{~mm} \pm 0.11$; female, $4.88 \mathrm{~mm} \pm 0.08$ ) were maintained at $25 \pm 1$

$148{ }^{\circ} \mathrm{C}$ under a 12:12 light:dark regime for $48 \mathrm{~h}$ and starved in continuously aerated $30 \mathrm{~L}$ tanks

149 containing dechlorinated tap water. The focal prey, Culex pipiens complex larvae (4.33 $\mathrm{mm} \pm$

150 0.18) were cultured using egg rafts collected from artificial containers on the University campus,

151 and reared to the desired size class in the same laboratory using a diet of crushed rabbit pellets

152 (Agricol, Port Elizabeth), supplied ad libitum.

153 Five predator treatments were designated using adult male and ovigerous female L. raynerae: (1)

154 female; (2) male; (3) female + female; (4) male + male, and; (5) female + male. Larval C. pipiens 
155 were established at five prey densities $(2,4,8,16,32 ; n=4$ per density) in $80 \mathrm{~mL}$ arenas of 5.6

$156 \mathrm{~cm}$ diameter containing dechlorinated tap water from a continuously aerated source, two hours

157 before the addition of predators in the laboratory $\left(25 \pm 1^{\circ} \mathrm{C}\right)$. Once predators were added they

158 were allowed to feed undisturbed for five hours during light conditions, after which they were

159 removed and remaining live prey counted to derive those killed. Controls consisted of four

160 replicates at each density in the absence of predators to quantify background mortality rates.

161 Data analyses

162 All statistical analyses were performed in R v3.5.1 (R Core Team 2018). Generalised linear

163 models (GLMs) assuming a Poisson error distribution were used to test for differences in overall

164 prey consumption among all observed predator groups (i.e. 5 levels including single predator

165 treatments) and prey supplies (i.e. 5 levels). We did not find evidence of residual overdispersion

166 in relation to degrees of freedom in GLMs. Non-significant terms and interactions were removed

167 stepwise from the model to facilitate parsimony, with $\chi^{2}$ used for model simplification via

168 deviance analyses (Crawley 2007). Tukey’s post-hoc tests were employed for multiple pairwise

169 comparisons using the 'emmeans' package in R (Lenth 2019).

170 We generated predictions of multiple predator consumption based on single predator treatments

171 to examine emergent MPEs between conspecifics using the multiplicative risk model (Soluk

172 1993):

173

$$
C_{a b}=N_{p}\left(P_{a}+P_{b}-P_{a} P_{b}\right)
$$

175 where $C_{a b}$ is the predicted consumption under each prey density $\left(N_{p}\right)$ and $P$ represents the 176 probabilities of being consumed by predators $a$ and $b$. To capture variability in underlying 
177 consumption data, we paired single predator replicates (i.e., $n=4$ per predicted group). This

178 model is applicable to additive experimental designs and accounts for prey removal by individual

179 predators, given a prey item eaten by one predator is no longer available for others. Three-way

180 beta regression via the 'betareg' package was used to examine observed and predicted

181 proportional consumption with respect to the multiple predator groups (i.e. 3 levels), prey

182 supplies (i.e. 5 levels) and a model evaluation factor (i.e. 2 levels; observed and predicted).

183 Proportions were transformed prior to analyses to remove 0 and 1 values and satisfy model

184 assumptions (Smithson \& Verkuilen 2006; Cribari-Neto \& Zeileis 2010):

185

$$
y_{t}=(y(n-1)+0.5) / n
$$

187 where $n$ is the sample size. Whilst the pooling of 'observed' and 'predicted' consumption rates 188 renders the single 'predator' and 'prey density' terms meaningless (see Vance-Chalcraft \& Soluk 189 2005), their two- or three-way interaction with the model evaluation factor indicates whether 190 MPEs are different among predator pairings and prey densities. Nested likelihood ratio tests were 191 employed to quantify the significance of main effects using the 'Imtest' package (Zeileis \& 192 Hothorn 2002), with Tukey's post-hoc comparisons used for pairwise comparisons (as above).

193 To further examine the intensity of intraspecific interactions between copepod sexes, a 194 substitutive model was used to predict prey survival rates in the mixed female-male predator 195 pairs, based on paired observations of survival rates in female-female and male-male pairs 196 (Griffen 2006):

$$
E_{(1,1)}=\sqrt{F_{(1,1)} \times M_{(1,1)}}
$$


199 where $F_{(1,1)}$ and $M_{(1,1)}$ are the observed survival rates in conspecific pairs of female and male 200 copepods, respectively. Two-way beta regression on proportioned survival (transformed as per 201 Eqn. 2) was then used to detect emergent MPEs with respect to prey density (5 levels) and the 202 model evaluation factor considering observations and predictions (2 levels). As before, the 203 pooling of 'observed' and 'predicted' levels rendered the single 'prey density' term 204 uninformative, however the presence of an interaction would signal MPE differences with 205 respect to survival rates among prey densities. Nested likelihood ratio tests were used as before 206 to infer significance.

207 We next compared transformed proportional consumption predictions between the additive (Eqn.

208 1) and substitutive (Eqn. 3) models for the mixed-sex treatment group using two-way beta 209 regression, with prey density (5 levels) and model type (2 levels) as predictor variables. Nested 210 likelihood ratio tests were again used for significance inference.

211 Functional response analyses were undertaken phenomenologically using the 'frair' package in R 212 (Pritchard et al. 2017). Logistic regression of the proportion of prey consumed as a function of 213 prey density was used to deduce functional response types. A Type II functional response is 214 characterised by a significantly negative first order term, whilst a Type III functional response is 215 characterised by a significantly positive first order term followed by a significantly negative 216 second order term (Solomon 1949; Holling 1959). As prey were not replaced as they were 217 consumed, we fit Rogers' random predator equation for depleting prey densities (Rogers 1972; 218 Trexler et al. 1998; Juliano, 2001):

$$
N_{e}=N_{0}\left(1-\exp \left(a\left(N_{e} h-T\right)\right)\right)
$$


221 where $N_{e}$ is the number of prey eaten, $N_{0}$ is the initial density of prey, $a$ is the attack constant, $h$

222 is the handling time and $T$ is the total experimental period. The Lambert $\mathrm{W}$ function was used to 223 allow model fitting (Bolker 2008). Predicted consumption estimates (see Eqn. 1) were rounded

224 as fitting Eqn. 4 using maximum likelihood estimation requires integer data. We used the 225 difference method, based on indicator variables (see Juliano, 2001), to undertake pairwise 226 comparisons of functional responses with respect to the attack rate and handling time parameters.

227 Here, we did not adjust $p$-values for multiplicity as not all treatment pairs were logically 228 comparable. Significance was inferred at the $95 \%$ confidence interval in all analyses.

230 Results

231 Observed consumption

232 Prey survival in controls exceeded 99\%, and so all experimental deaths were attributed to 233 predation by L. raynerae. For observed predator groups, overall, consumption was significantly 234 affected by the 'predator' treatment (Table 1). There was no significant difference in 235 consumption between male and females when present singularly $(p=0.40)$, yet two females 236 consumed significantly more than two males $(p=0.04)$. However, no significant difference was 237 detected between the mixed multiple predator treatment and either single-sex multiple predator 238 treatments (two males, $p=0.25$; two females, $p=0.92$ ). Predation increased significantly overall 239 with greater prey densities (Table 1). Consumption at prey densities of 32 was significantly 240 higher than under prey densities of 2, 4 and 8 (all $p<0.05$ ), whilst consumption at densities of

24116 was significantly greater than at prey densities of 2 and 4 (both $p<0.05$ ). Similarly, 
242 consumption at densities of 8 significantly exceeded that under densities of $2(p=0.03)$. The

243 non-significant 'predator $\times$ prey density' interaction was removed from the final model (Table

244 1), indicating that differences among predator groups were consistent across prey density levels.

245 Additive model

246 The observed proportions of prey eaten were significantly lower than those predicted by the

247 multiplicative risk model overall, indicating antagonistic interactions between intraspecific

248 predator pairs (Table 2; Fig. 1). This is congruent with overall prey risk reductions. There were

249 no significant two- or three-way interaction terms considering the multiplicative risk model

250 (Table 2). Accordingly, MPEs resulting in prey risk reductions were consistent across predator

251 pairings and prey densities. Nevertheless, the strength of male-male prey risk reductions tended

252 to be higher than either the female-female or mixed groupings at the highest prey densities,

253 whilst female-female risk reductions were strongest at lower densities (Fig. 1).

\section{Substitutive model}

255 The predictions from the substitutive model of prey survival for mixed-sex copepod treatment

256 groups did not differ significantly from survival rates observed overall, and there was no

257 significant 'prey density $\times$ model' interaction term (Table 3). Therefore, survivorship under

258 mixed copepod groups was well-predicted from single-sex conspecific pairs irrespective of prey

259 density (Fig. 2).

\section{Model comparisons}

261 Overall, the substitutive model predicted significantly lower estimates of prey mortality as 262 compared to the additive model for the mixed-sex copepod groups (Table 4; Fig. 3). This effect 263 was consistent across prey densities, owing to a non-significant interaction term (Table 4). 
264 Accordingly, this aligns with higher predictability of multiple predator consumption by the 265 substitutive as compared to additive model (see above).

266 Functional response

267 Type II functional responses were detected across all observed and predicted predator treatments

268 (Table 5; Fig. 4). There was no significant difference between attack rates $(z=0.72, p=0.48)$ or 269 handling times $(z=0.88, p=0.38)$ between single male and single female treatments (Fig. 4A). 270 For multiple predator groups, predicted functional responses tended to be lower than those 271 observed, indicating antagonistic interactions in multiple predator treatment groups (Fig. 4B, C, 272 D). However, predicted functional response parameters were not significantly different from 273 those observed in the double female treatment $(a, \mathrm{z}=1.78, p=0.08 ; h, z=0.56, p=0.57)$ (Fig. 274 4B). Further, observed attack rates were not significantly different from those predicted in the 275 double male treatment $(z=0.66, p=0.51)$, however, observed handling times were significantly 276 longer than those predicted here $(z=2.75, p=0.01)$, indicating antagonistic male-male 277 interactions which significantly reduced maximum feeding rates (Fig. 4C). Predicted functional 278 response parameters were not significantly different from those observed in the mixed female279 male predator treatment groups $(a, z=1.14, p=0.26 ; h, z=0.59, p=0.56)$ (Fig. 4D).

\section{Discussion}

282 In this study, we determine the effects of sex demographics for the quantification of intraspecific 283 MPEs. Conspecific pairs of L. raynerae exhibited significant antagonistic interactions overall, 284 culminating in prey risk reductions for $C$. pipiens larval prey. Whilst MPE differences among 285 predator groupings lacked statistical clarity, antagonisms tended to be strongest for male-male 
286 interacting copepods, whereby observed predation rates were substantially reduced under higher 287 prey densities as compared to model predictions. Evidenced by functional response analyses, this 288 manifested in significant increases in observed handling times for prey relative to those predicted 289 under male copepod pairs, indicating antagonisms which reduced maximum feeding rates.

290 Conversely, female-female conspecific pairs tended to reduce prey risk under lower prey 291 densities, in turn driving reductions in attack rates compared to predictions, yet these effects 292 were not statistically clear. Mixed female-male predator treatment observations were relatively 293 closely predicted under both additive and substitutive models. These findings are important, 294 given the distinct lack of experimental consideration for demographic effects on MPEs across 295 resource densities.

296 Ovigerous female copepods were significantly more voracious than male L. raynerae in the 297 present study when comparing female-female and male-male units, yet not for single predator 298 treatments. Cuthbert et al. (2019b) found higher energetic demands for progeny development to 299 drive greater interaction strengths by gravid female calanoid copepods, corroborating evidence 300 from other copepod groups (Laybourn-Parry et al. 1988). Accordingly, overall predatory impact 301 in temporary pond ecosystems is likely to be exacerbated as predator sex demographics 302 transition to female-skewed ratios, which have been shown to develop over time (Wasserman et 303 al. 2018). Owing to the numerical dominance of L. raynerae in temporary pond ecosystems 304 resulting from internal recruitment dynamics (Wasserman et al. 2018), alongside high per capita 305 offtake rates and high trophic positioning (Dalu et al. 2016; Wasserman et al. 2016b; Cuthbert et 306 al. 2018a), such quantifications of sex demographic implications for conspecific interactions 307 provide important insights in a temporal prey risk context within these understudied systems in 308 arid environments. 
Consumptive predictions from the multiplicative risk model were significantly greater than predation rates experimentally observed for multiple predator groups. Accordingly, antagonistic

311 interactions between copepods resulted in prey risk reductions overall, with a lack of significant

312 evidence for negative MPEs being dependent on the composition of predator pairs or prey

313 densities. Nevertheless, subtle differences were emergent among predator treatment pairs and

314 prey densities, with the magnitude of antagonisms by female-female pairs most pronounced at

315 low prey densities. This, in turn, resulted in substantial reductions in attack rates for female-

316 female treatments towards larval mosquito prey, although non-significantly. Conversely, male-

317 male pair predation was more evidently reduced under high prey densities, with significant

318 increases in prey handling times. In turn, this interference resulted in reductions in maximum

319 feeding rates. Whilst the specific behavioural mechanisms for these differences require further

320 elucidation, it is possible that differences relate to mate searching processes. In certain

321 zooplankton species, greater activity levels by males compared to females has been shown to

322 make males more vulnerable to predation (Kiørboe 2006, Gusmão et al. 2013), and male $L$.

323 raynerae have been shown to be significantly more motile than females (Cuthbert et al. 2019a).

324 The elevated motility rates exhibited by males may therefore increase the potential for male-male

325 encounter rates which could elicit interference and drive prey risk reductions, and particularly

326 under higher prey densities. Nevertheless, whilst differences in predicted and observed

327 functional response parameters were observed in the present study, Type II functional responses

328 were displayed by copepods across all treatment groups. Therefore, MPEs did not impart low

329 density refuge effects for prey, with the potential to accordingly drive stabilising effects (Hassell

330 1978; Dick et al. 2014). For medically important prey such as mosquitoes, Type II functional 
331 responses may facilitate population extirpations under certain conditions, in turn benefitting

332 public health.

333 A broad range of statistical approaches have been proposed to quantify the nature of multiple

334 predator interactions (Abrams \& Ginzburg 2000), and debate exists regarding the choice between

335 prey-dependent and predator-dependent models. Several predator-dependent functional response

336 models which directly account for predator density in parameterisation are available (Beddington

337 1975; Crowley \& Martin 1989; DeAngelis et al. 1975), and their use may provide a better fit to a

338 given dataset than a prey-dependent model (Médoc et al. 2013), particularly where prey densities

339 are high and predator density does not affect predation rates (Skalski \& Gilliam 2001).

340 Nonetheless, in the present study, predictions were based on consumption rates from single

341 predator groups using the multiplicative risk model. This follows a similar approach to many

342 other studies where the multiplicative risk model is commonly used based on per capita

343 consumption rates alone (e.g., Vance-Chalcraft \& Soluk 2005; Wasserman et al. 2016b; but see

344 also Sentis \& Boukal 2018), and provides useful comparative insights into the strength of non-

345 trophic interactions across a range of factorial experimental conditions.

346 In the present study, predictions for mixed female-male treatment groups were derived and

347 compared across both additive and substitutive models. Prey survival rates predicted from the

348 substitutive model were closer to empirical observations, and were significantly lower than those

349 predicted from the additive multiplicative risk model. The significant difference between models

350 is unsurprising, with the substitutive model inferences based on predation rates from the single-

351 sex predator pairs, where antagonisms were already prevalent. Conversely, the additive model is

352 based on predators singularly, whereby per capita interaction strengths were intensified in the

353 present study. These results corroborate with those from Lampropoulos et al. (2013), where the 
354 substitutive model was more closely aligned with observed predation rates. Additive designs

355 have been criticised due to reduced explanatory power given the inherent difference in predator

356 numbers (Sih et al. 1998; Griffen 2006), whilst mechanistic interpretation of substitutive designs

357 is made difficult by differences in proportional densities between predators (Inouye 2001;

358 Griffen 2006). Therefore, comparisons of these modelling approaches across experimental

359 contexts is of importance to gain more holistic understandings of predator-predator interactions.

360 Furthermore, Sentis and Boukal (2018) found the multiplicative risk model to underestimate

361 predation rates when prey densities are high or prey depletion is substantial, and therefore the

362 magnitude of antagonistic MPEs here may be considered conservative estimates with regards to

363 risk reduction.

364 Whilst the use of simplified experimental arenas has the potential to enhance the prevalence of

365 negative MPEs and limits mechanistic interpretations (Schmitz 2007), applications of

366 comparative functional responses can still yield powerful predictions of interaction strengths in a

367 multiple predator context. Temporary pond ecosystems in arid regions are poorly understood at

368 present, with a relatively small body of literature examining trophic dynamics within these

369 systems (O’Neill \& Thorp 2014; Dalu et al. 2016; Wasserman et al. 2016a; Cuthbert et al.

370 2019b). The present study demonstrated significant overall antagonism in interacting conspecific

371 copepods and, although lacking statistical clarity, identified sex demographics as a potential

372 mediator of MPEs. Future studies should further integrate differences in population

373 demographics, such as sex ratios and life history stages, into quantifications of community

374 dynamics across multiple habitat types and taxonomic groups. 


\section{Author contributions}

$377 \mathrm{RC}, \mathrm{TD}, \mathrm{RW}, \mathrm{OW}$ and JD conceived and designed the experiments. RC and TD performed the

378 experiments. RC analysed the data. RC, TD, OW, WF and AC contributed materials and analysis

379 tools. RC wrote the first draft of paper. All authors prepared revised versions

381 Acknowledgements

382 This study was funded by the Department for the Economy, Northern Ireland. We extend

383 gratitude to Rhodes University for the provision of laboratory facilities. We acknowledge use of

384 infrastructure and equipment provided by the South African Institute for Aquatic Biodiversity

385 (SAIAB) Research Platform and the funding channelled through the National Research

386 Foundation - SAIAB Institutional Support system. This study was partly funded by the National

387 Research Foundation - South African Research Chairs Initiative of the Department of Science

388 and Innovation (Inland Fisheries and Freshwater Ecology, Grant No. 110507).

\section{References}

391 Abrams PA (1982) Functional responses of optimal foragers. Am Nat 120:382-390

392 Abrams PA (2000) The evolution of predator-prey interactions: theory and evidence. Ann Rev

$393 \quad$ Ecol Syst 31:79-105

394 Abrams PA \& Ginzburg LR (2000) The nature of predation: prey dependent, ratio dependent or 395 neither? Trends Ecol Evol 15:337-341 
Barrios-O’Neill D, Dick JTA, Emmerson MC, Ricciardi A, MacIsaac HJ, Alexander ME, Bovy HC (2014) Fortune favours the bold: a higher predator reduces the impact of a native but not an invasive intermediate predator. J Anim Ecol 83:693-701

Beddington JR (1975) Mutual interference between parasites or predators and its effect on searching efficiency. J. Anim. Ecol. 44:331-340

Bolker BM (2008) Ecological models and data in R. Princeton University Press, Princeton

Bolker BM, Holyoak M, Křivan V, Rowe L, Schmitz O (2003) Connecting theoretical and empirical studies of trait-mediated interactions. Ecology 84:1101-1114

Chang GC (1996) Comparison of single versus multiple species of generalist predators for biological control. Environ Entomol 25:207-212

Crawley MJ (2007) The R book. Wiley \& Sons, Chichester

Cribari-Neto F, Zeileis A (2010) Beta regression in R. J Stat Softw 34:1-24

Crowley PH, Martin EK (1989) Functional responses and interference within and between year classes of a dragonfly population. J North Am Benthol Soc 8:211-221

Cuthbert RN, Dalu T, Wasserman RJ, Dick JTA, Callaghan A, Froneman PW, Weyl OLF (2019a) Quantifying reproductive state and predator effects on copepod motility in ephemeral ecosystems. In press.

Cuthbert RN, Dalu T, Wasserman RJ, Callaghan A, Weyl OLF, Dick JTA (2018a) Calanoid copepods: an overlooked tool in the control of disease vector mosquitoes. J Med Entomol $25: 1656-1658$ 
Cuthbert RN, Dalu T, Wasserman RJ, Weyl OLF, Callaghan A, Froneman PW, Dick JTA (2019b) Sex-skewed trophic impacts in ephemeral wetlands. Freshwater Biol 64:359-366

Cuthbert R N, Dick JTA, Callaghan A, Dickey JWE (2018b) Biological control agent selection under environmental change using functional responses, abundances and fecundities; the Relative Control Potential (RCP) metric. Biol Control 121:50-57

Dalu T, Weyl OLF, Froneman PW, Wasserman RJ (2016) Trophic interactions in an Austral temperate ephemeral pond inferred using stable isotope analysis. Hydrobiologia 768:8194

DeAngelis DL, Goldstein RA, O’Neill RV (1975) A model for tropic interaction. Ecology $56: 881-892$

Dick JTA, Alexander ME, Jeschke JM, Ricciardi A, MacIsaac HJ, Robinson TB, Kumschick S, Weyl OLF, Dunn AM, Hatcher MJ, Paterson RA, Farnsworth KD, Richardson DM (2014) Advancing impact prediction and hypothesis testing in invasion ecology using a comparative functional response approach. Biol Invasions 16:735-753

Estes JA, Terborgh J, Brashares J S, Power ME, Berger J, Bond WJ, Carpenter SR, Essington TE, Holt RD, Jackson JB, Marquis RJ, Oksanen L, Oksanen T, Paine RT, Pikitch EK, Ripple WJ, Sandin SA, Scheffer M, Schoener TW, Shurin JB, Shoener TW, Shurin JB, Sinclair AR, Soulé ME, Virtanen R, Wardle DA (2011) Trophic downgrading of planet earth. Science. 333:301-306

Griffen BD (2006) Detecting emergent effects of multiple predator species. Oecologia 148:702709 
437 Gusmão LFM, McKinnon AD, Richardson AJ (2013) No evidence of predation causing femalebiased sex ratios in marine pelagic copepods. Mar Ecol Prog Ser, 482:279-298

439 Hairston NG, Smith FE, Slobodkin LB (1960) Community structure, population control, and 440 competition. Am Nat, 94:421-425

441 Harvey BC, White JL, Nakamoto RJ (2004) An emergent multiple predator effect may enhance 442 biotic resistance in a stream fish assemblage. Ecology 85:127-133

443 Hassell MP (1978) The dynamics of arthropod predator-prey systems. Princeton University 444 Press, New York

445 Holling C (1959) The components of predation as revealed by a study of small-mammal 446 predation of the European Pine Sawfly. Can Entomol 91:293-320

447 Inouye BD (2001) Response surface experimental designs for investigating interspecific $448 \quad$ competition. Ecology 82:2696-2706

449 Juliano SA (2001) Non-linear curve fitting: predation and functional response curves. In: 450 Scheiner SM, Gurevitch J (eds) Design and analysis of ecological experiments. Oxford $451 \quad$ University Press, Oxford

452 Kiørboe T (2006) Sex, sex-ratios, and the dynamics of pelagic copepod populations. Oecologia 453 148:40-50

454 Lampropoulos PD, Perdikis DCh, Fantinou AA (2013) Are multiple predator effects directed by 455 prey availability? Basic Appl Ecol 14:605-613 
Laybourn-Parry J, Abdullahi BA, Tinson SV (1988) Temperature-dependent energy partitioning in the benthic copepods Acanthocyclops viridis and Macrocyclops albidus. Can J Zool $66: 2709-2713$

Lenth R. (2019). emmeans: Estimated Marginal Means, aka Least-Squares Means. R Package

Losey JE, Denno RF (1998) Positive predator-predator interactions: enhanced predation rates and synergistic suppression of aphid populations. Ecol 79:2143-2152

McCoy, MW, Stier AC, Osenberg CW (2012) Emergent effects of multiple predators on prey survival: the importance of depletion and the functional response. Ecol Lett 15:14491456

Médoc V, Spataro T, Arditi R (2013) Prey: predator ratio dependence in the functional response of a freshwater amphipod. Freshwater Biol 58:858-865

O’Gorman EJ, Enright RA, Emmerson MC (2008) Predator diversity enhances secondary production and decreases the likelihood of trophic cascades. Oecologia 158:557-567

O’Neill, BJ, Thorp, JH (2014) Untangling food-web structure in an ephemeral ecosystem. Freshwater Biol. 59:1462-1473

Porter-Whitaker AE, Rehage JS, Liston SE, Loftus WF (2012) Multiple predator effects and native prey responses to two non-native Everglades cichlids. Ecol Freshwater Fish $21: 375-385$

Pritchard DW, Paterson RB, Helene C, Barrios-O’Neill D (2017) FRAIR: an R package for fitting and comparing consumer functional responses. Methods Ecol Evol 8:1528-1534

R Core Team (2018) R: A language and environment for statistical computing. Vienna 
477 Rogers D (1972) Random search and insect population models. J Anim Ecol 41:369-383

478 Rosenheim JA, Kaya HK, Ehler LE, Marois JJ, Jaffee BA (1995) Intraguild predation among

479 biological- control agents - theory and evidence. Biol Control 5:303-335

480 Schmitz OJ (2007) Predator diversity and trophic interactions. Ecology 88:2415-2426

481 Sentis A, Boukal DS (2018) On the use of functional responses to quantify emergent multiple

482 predator effects. Sci Rep 8:11787

483 Sih A, Crowley P, McPeek M, Petranka J, Strohmeier K (1985) Predation, competition and prey

484 communities: a review of field experiments. Annu Rev Ecol Syst 16:269-311

485 Sih A, Englund G, Wooster D (1998) Emergent impacts of multiple predators on prey. Trends

$486 \quad$ Ecol Evol 13:350-355

487 Skalski GT, Gilliam JF (2001) Functional responses with predator interference: viable alternatives to the Holling type II model. Ecology 82:3083-3092.

489 Smithson M, Verkuilen JA (2006) Better lemon squeezer? Maximum-likelihood regression with 490 beta-distributed dependent variables. Psychol Methods 11:54-71

491 Solomon ME (1949) The natural control of animal populations. J Anim Ecol 18:1-35

492 Soluk DA (1993) Multiple predator effects: predicting combined functional response of stream 493 fish and invertebrate predators. Ecology 74:219-225

494 Suárez-Morales E, Wasserman RJ, Dalu T (2015) A new species of Lovenula Schmeil 495 (Copepoda Calanoida, Diaptomidae) from East Cape Province, South Africa. Crustaceana 496 $88: 324-342$ 
497 Trexler JC, McCulloch CE, Travis J (1988) How can the functional response best be determined?

$498 \quad$ Oecologia 76:206-214

499 Vance-Chalcraft HD, Soluk DA (2005) Multiple predator effects result in risk reduction for prey 500 across multiple prey densities. Oecologia 144:472-480

501 Wasserman RJ, Alexander ME, Barrios-O’Neill D, Weyl OLF, Dalu T (2016a) Using functional 502 responses to assess predator hatching phenology implications for pioneering prey in arid temporary pools. J Plankt Res 38:154-158

504 Wasserman RJ, Alexander ME, Dalu T, Ellender BR, Kaiser H, Weyl OLF (2016b) Using

505 functional responses to quantify interaction effects among predators. Funct Ecol

506 30:1988-1998

507 Wasserman RJ, Weston M, Weyl OLF, Froneman PW, Welch RJ, Vink TJ Dalu T (2018) Sacrificial males: the potential role of copulation and predation in contributing to copepod sex-skewed ratios. Oikos 127:970-980

Waterkeyn A, Grillas P, Brendonck L (2016) Experimental test of the ecosystem impacts of the keystone predator Triops cancriformis (Branchiopoda: Notostraca) in temporary ponds. Freshwater Biol 61:1392-1404

513 Werner EE, Peacor SD (2003) A review of trait-mediated indirect interactions in ecological communities. Ecology 84:1083-1100

515 Zeileis A, Hothorn T (2002) Diagnostic checking in regression relationships. R News 2:7-10 
518 Table 1. Main effects resulting from deviance analysis of Poisson generalised linear model

519 considering raw consumption counts according to the predator (P) and prey density (D) treatment 520 terms.

\begin{tabular}{lrrr}
\hline Source & $\chi^{2}$ & df & $p$ \\
\hline P & 15.16 & 4 & 0.004 \\
D & 44.56 & 4 & $<0.001$ \\
P $\times$ D & 10.51 & 16 & 0.839 \\
\hline
\end{tabular}

521

522

523

524

525

526

527

528

529

530

531

532 
533 Table 2. Main effects resulting from likelihood ratio tests of beta regression analysis considering

534 observed and predicted multiple predator predation rates from the multiplicative risk model (M)

535 among predator pairs (P) and prey densities (D).

\begin{tabular}{lrrr}
\hline Source & $\chi^{2}$ & df & $p$ \\
\hline $\mathrm{P}$ & 4.46 & 2 & 0.108 \\
$\mathrm{D}$ & 94.91 & 4 & $<0.001$ \\
$\mathrm{M}$ & 4.50 & 1 & 0.034 \\
$\mathrm{P} \times \mathrm{D}$ & 2.22 & 8 & 0.973 \\
$\mathrm{P} \times \mathrm{M}$ & 0.35 & 2 & 0.838 \\
$\mathrm{D} \times \mathrm{M}$ & 0.66 & 4 & 0.957 \\
$\mathrm{P} \times \mathrm{D} \times \mathrm{M}$ & 7.68 & 8 & 0.466
\end{tabular}

536

537

538

539

540

541

542

543

544 
545 Table 3. Main effects resulting from likelihood ratio tests of beta regression analysis considering

546 observed and predicted survival rates from the substitutive model (M) for mixed female-male

547 intraspecific predator pairs across prey densities (D).

\begin{tabular}{lrrr}
\hline Source & $\chi^{2}$ & df & $p$ \\
\hline $\mathrm{D}$ & 31.98 & 4 & $<0.001$ \\
$\mathrm{M}$ & 0.38 & 1 & 0.540 \\
$\mathrm{D} \times \mathrm{M}$ & 5.61 & 4 & 0.230 \\
\hline
\end{tabular}

548

549

550

551

552

553

554

555

556

557

558 
559 Table 4. Main effects resulting from likelihood ratio tests of beta regression analysis considering

560 predicted mortality rates between the additive and substitutive models (M) for mixed

561 intraspecific predator pairs across prey densities (D).

\begin{tabular}{lrrr}
\hline Source & $\chi^{2}$ & df & $p$ \\
\hline $\mathrm{D}$ & 28.99 & 4 & $<0.001$ \\
$\mathrm{M}$ & 4.97 & 1 & 0.026 \\
$\mathrm{D} \times \mathrm{M}$ & 0.31 & 4 & 0.989
\end{tabular}

562

563

564

565

566

567

568

569

570

571

572

573 
574 Table 5. First order terms and significance levels resulting from logistic regression of the

575 proportion of prey eaten as a function of prey density across differing predator treatments

576 (female, F; male, M) and models (observed, O; predicted, P). Functional response parameter

577 estimates (attack rate, $a$; handling time, $h$ ) are shown alongside significance levels resulting from

578 Rogers' random predator equation.

\begin{tabular}{|c|c|c|c|c|c|c|}
\hline Predator & Observed/Predicted & First order term, $p$ & $a$ & $p$ & $h$ & $p$ \\
\hline $\mathrm{F}$ & $\mathrm{O}$ & $-0.07,<0.001$ & 1.85 & 0.04 & 0.22 & $<0.001$ \\
\hline M & $\mathrm{P}$ & $-0.06,<0.001$ & 1.07 & 0.10 & 0.30 & $<0.001$ \\
\hline$F+F$ & $\mathrm{O}$ & $-0.04,<0.001$ & 1.00 & 0.002 & 0.10 & $<0.001$ \\
\hline$F+F$ & $\mathrm{P}$ & $-0.07,<0.001$ & 3.37 & 0.01 & 0.12 & $<0.001$ \\
\hline$M+M$ & $\mathrm{O}$ & $-0.11,<0.001$ & 4.18 & 0.11 & 0.35 & $<0.001$ \\
\hline$M+M$ & $\mathrm{P}$ & $-0.06,<0.001$ & 2.34 & 0.03 & 0.17 & $<0.001$ \\
\hline $\mathrm{F}+\mathrm{M}$ & $\mathrm{O}$ & $-0.06,<0.001$ & 1.39 & 0.01 & 0.16 & $<0.001$ \\
\hline $\mathrm{F}+\mathrm{M}$ & $\mathrm{P}$ & $-0.07,<0.001$ & 2.88 & 0.02 & 0.14 & $<0.001$ \\
\hline
\end{tabular}


584 Fig. 1. Observed and predicted proportional prey consumption under different intraspecific

585 predator pairings and prey densities. Predictions are based on the multiplicative risk model.

586 Means are \pm SE ( $n=4$ per experimental group). Predicted predator performance was calculated

587 from individuals (Eqn. 1).

588

589 Fig. 2. Observed and predicted proportional prey survivability in the mixed female-male predator

590 pairing. Predictions are based on the substitutive model. Means are \pm SE $(n=4$ per experimental 591 group). Predicted prey survival was calculated from predation by single-sex conspecific pairs 592 (Eqn. 3).

593

594 Fig. 3. Predictions of proportional prey consumption in the mixed female-male predator pairing,

595 between the additive and substitutive models across prey densities. Means are \pm SE $(n=4$ per 596 experimental group).

Fig. 4. Observed functional responses of single predators, and observed and predicted multiple

599 predator functional responses. Means are \pm 1 SE ( $n=4$ per experimental group). Predicted

600 predator performance was calculated from individuals using the rounded multiplicative risk

601 model (Eqn. 1). 